\title{
Bifurcatriol, a New Antiprotozoal Acyclic Diterpene from the Brown Alga Bifurcaria bifurcata
}

\author{
Vangelis Smyrniotopoulos ${ }^{1}$, Christian Merten ${ }^{2}$, Marcel Kaiser ${ }^{3,4}$ and Deniz Tasdemir ${ }^{1,5, *}$ \\ 1 School of Chemistry, National University of Ireland Galway, University Road, Galway, Ireland; \\ vsmy@hotmail.com \\ 2 Lehrstuhl für Organische Chemie 2, Ruhr-Universität Bochum, Universitätsstraße 150, 44801 Bochum, \\ Germany; christian.merten@ruhr-uni-bochum.de \\ 3 Swiss Tropical and Public Health Institute, 4051 Basel, Switzerland; marcel.kaiser@unibas.ch \\ 4 University of Basel, 4003 Basel, Switzerland \\ 5 GEOMAR Centre for Marine Biotechnology (GEOMAR-Biotech), Research Unit Marine Natural Product \\ Chemistry, Research Division Marine Ecology, GEOMAR Helmholtz Centre for Ocean Research Kiel, \\ Am Kiel-Kanal 44, 24106 Kiel, Germany \\ * Correspondence: dtasdemir@geomar.de; Tel.: +49-431-6004430
}

Received: 19 June 2017; Accepted: 27 July 2017; Published: 2 August 2017

\begin{abstract}
Linear diterpenes that are commonly found in brown algae are of high chemotaxonomic and ecological importance. This study reports bifurcatriol (1), a new linear diterpene featuring two stereogenic centers isolated from the Irish brown alga Bifurcaria bifurcata. The gross structure of this new natural product was elucidated based on its spectroscopic data (IR, 1D and 2D-NMR, HRMS). Its absolute configuration was identified by experimental and computational vibrational circular dichroism (VCD) spectroscopy, combined with the calculation of ${ }^{13} \mathrm{C}-\mathrm{NMR}$ chemical shielding constants. Bifurcatriol (1) was tested for in vitro antiprotozoal activity towards a small panel of parasites (Plasmodium falciparum, Trypanosoma brucei rhodesiense, T. cruzi, and Leishmania donovani) and cytotoxicity against mammalian primary cells. The highest activity was exerted against the malaria parasite P. falciparum ( $\mathrm{IC}_{50}$ value $0.65 \mu \mathrm{g} / \mathrm{mL}$ ) with low cytotoxicity $\left(\mathrm{IC}_{50}\right.$ value $56.6 \mu \mathrm{g} / \mathrm{mL}$ ). To our knowledge, this is the first successful application of VCD and DP4 probability analysis of the calculated ${ }^{13} \mathrm{C}$-NMR chemical shifts for the simultaneous assignment of the absolute configuration of multiple stereogenic centers in a long-chain acyclic natural product.
\end{abstract}

Keywords: Bifurcaria bifurcata; diterpene; marine alga; VCD; absolute configuration; antiprotozoal

\section{Introduction}

Acyclic terpenes comprise a very small yet fundamental fraction of terpenes, the largest class of natural products with the highest structural and stereochemical diversity [1]. Terpene biosynthesis involves them as intermediates originating from enzymatic elongation and modification of few universal linear and non-chiral isoprenoid precursors [2,3]. The immense chemodiversity of terpenes finally emerges through a more evolved enzymatic machinery of additional cyclization and rearrangements as compared to the pathways of their acyclic primordial congeners [2,4]. Linear terpenes also encompass various modifications of the simple parent acyclic carbon skeletons. They display numerous ecological roles (e.g., defensive or communicational) and are represented in all terpene classes, both in terrestrial and marine macro- and micro-organisms. The properties and activities associated with these roles underline their great significance in industry, agriculture, and medicine [5-7].

Marine algal metabolites account for $13 \%$ of marine natural products, with terpenoids prevailing at a percentage over 50\% [8,9]. Geranylgeraniol derivatives comprise some of the earliest compounds 
isolated from the order Fucales that comprise about a third of brown algal metabolites [10]. Recent literature surveys on the family Sargassaceae indicate Bifurcaria bifurcata (Velley) R. Ross to be one of the most prolific sources of bioactive secondary metabolites. This species accounts for $8 \%$ of the total metabolites of the family, with acyclic diterpenes being the main constituents of the organic extracts $[11,12]$. Many of the geranylgeraniol-derived linear diterpenes are of high chemotaxonomic and ecological importance with demonstrated antifouling, antimicrobial, antimitotic, and cytotoxic activities [11]. Unfortunately, unambiguous assignment of the absolute configuration of all stereogenic centers in many linear diterpenes has not yet been accomplished due to their molecular features [11].

It is commonly accepted that chirality, an amplifier of molecular diversity, has triggered evolution in nature by rendering most physiological interactions regio- and stereospecific $[13,14]$. Bioactive secondary metabolites are principally chiral compounds, necessitating the unambiguous determination of their absolute configuration (AC) and conformations, in order to gain insights into their mode of action or biosynthetic origin [14,15]. The most frequently used methods for designation of the AC in chiral molecules to date are NMR anisotropy and X-ray crystallography. However, their application in natural products is not always feasible. The alternation of NMR signals requires the use of a chiral anisotropy reagent while the formation of a single crystal is a prerequisite for X-ray crystallography [13]. The use of nondestructive chiroptical methods, such as electronic circular dichroism (ECD) and vibrational circular dichroism (VCD), as alternatives has recently gained popularity. In particular, the combination of stereochemical sensitivity with the rich structural content of vibrational spectra by VCD and Raman Optical Activity (ROA) has brought forward very reliable approaches for the AC determination of natural products $[16,17]$. In addition, the conformational sensitivity of vibrational spectroscopy allowed some insights into very interesting conformational variations in natural products [18] as well as peptides and other chiral molecules [19-21].

In continuation of our investigation of chemical constituents of seaweeds, we isolated a new linear diterpene bifurcatriol (1, Figure 1) from the Irish brown alga Bifurcaria bifurcata. In this paper, we describe its isolation, structure elucidation, including AC assignment, and in vitro antiprotozoal activity. Encouraged by the recent successful determination of the AC of two linear diterpenes, elegandiol (2) and bifurcane (3) with a single chiral carbon (C-13) from the same alga by VCD spectroscopy [22], we explored the applicability of this method to linear diterpenes bearing multiple stereogenic centers. The VCD-based AC assignment is further supported by ${ }^{13} \mathrm{C}-\mathrm{NMR}$ chemical shift calculations [23].

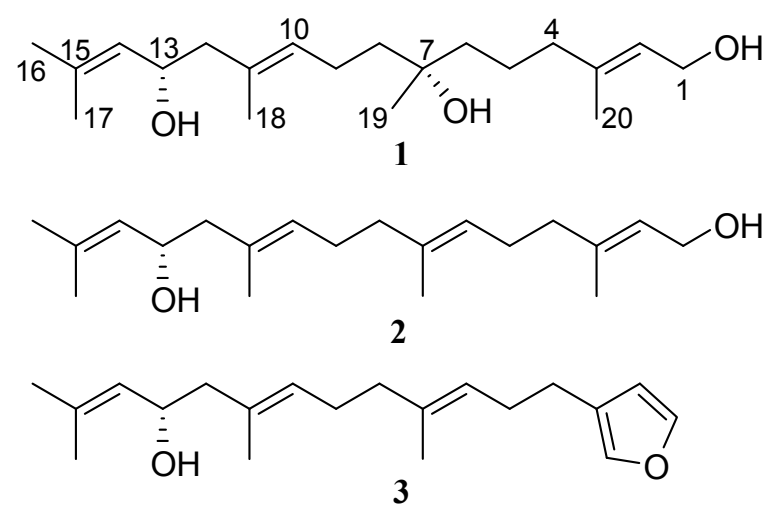

Figure 1. Structure of compounds (1-3) obtained from B. bifurcata.

\section{Results}

\subsection{Isolation and Structure Elucidation}

Algal fronds of B. bifurcata were collected from the shore of Kilkee, County Clare in western Ireland. The freeze-dried alga was successively extracted with $\mathrm{CH}_{2} \mathrm{Cl}_{2}$ and $\mathrm{MeOH}$. A modified solvent 
partition of the combined organic residues afforded the $n$-hexane, $\mathrm{CHCl}_{3}$, and aqueous subextracts. The $\mathrm{CHCl}_{3}$ subextract was subjected to repeated automated Flash and HPLC chromatography to yield pure bifurcatriol (1).

Bifurcatriol (1) was obtained as an optically active oil. Based on its HRESIMS, its molecular formula was identified as $\mathrm{C}_{20} \mathrm{H}_{36} \mathrm{O}_{3}$, indicating three degrees of unsaturation. Detailed analyses of ${ }^{1} \mathrm{H}$, ${ }^{13} \mathrm{C}-\mathrm{NMR}$, and $g \mathrm{HSQC}$ data (Table 1 and Figures S2, S3 and S5) revealed the presence of three olefinic methines $\left(\delta_{\mathrm{H}} / \delta_{\mathrm{C}} 5.39 / 123.6,5.25 / 128.6,5.13 / 127.5\right)$ and three quaternary $\mathrm{sp}^{2}$ carbons $\left(\delta_{\mathrm{C}} 131.6,134.8\right.$, $139.5)$, along with four olefinic methyl groups $\left(\delta_{\mathrm{H}} / \delta_{\mathrm{C}} 1.69 / 25.7,1.66 / 18.2,1.65 / 16.1,1.65 / 16.2\right)$ and one aliphatic methyl $\left(\delta_{\mathrm{H}} / \delta_{\mathrm{C}} 1.14 / 26.7\right)$. The IR spectrum displayed an intense absorption band at $v_{\max }$ $3354 \mathrm{~cm}^{-1}$, characteristic for the presence of hydroxyl functionality $(\mathrm{O}-\mathrm{H}$ stretch). This data was in accordance with the NMR signals attributable to an oxygenated methylene $\left(\delta_{\mathrm{H}} / \delta_{\mathrm{C}} 4.13 / 59.3\right)$, and an oxymethine $\left(\delta_{\mathrm{H}} / \delta_{\mathrm{C}} 4.41 / 65.9\right)$ group, in concurrence with a quaternary oxygen bearing carbon $\left(\delta_{\mathrm{C}} 72.7\right)$. The ${ }^{1} \mathrm{H}$ and ${ }^{13} \mathrm{C}-\mathrm{NMR}$ spectra also exhibited the resolved resonances of six methylenes $\left(\delta_{\mathrm{H}} / \delta_{\mathrm{C}} 2.00 / 39.9,1.45 / 22.0,1.40 / 41.7,1.49 / 41.3,2.07 / 22.8,2.11 / 48.1\right)$, thus indicating an acyclic diterpene skeleton.

Table 1. NMR spectroscopic data (500 MHz, $\left.\mathrm{CDCl}_{3}\right)$ of bifurcatriol (1)

\begin{tabular}{cccccc}
\hline Position & $\delta_{\mathrm{C}}$, Type & $\delta_{\mathbf{H}}$, Mult $(\boldsymbol{J}$ in Hz) & COSY & NOESY & HMBC $\left({ }^{\mathbf{1}} \mathbf{H} \rightarrow{ }^{\mathbf{1 3}} \mathbf{C}\right)$ \\
\hline 1 & $59.3, \mathrm{CH}_{2}$ & $4.13, \mathrm{~d}(6.8)$ & 2,20 & 20 & 2,3 \\
2 & $123.6, \mathrm{CH}$ & $5.39, \mathrm{t}(6.8)$ & 1,20 & 4 & $1,4,20$ \\
3 & $139.5, \mathrm{C}$ & & & & \\
4 & $39.9, \mathrm{CH}_{2}$ & $2.00, \mathrm{t}(7.0)$ & 5 & 2 & $2,3,5,6,20$ \\
5 & $22.0, \mathrm{CH}_{2}$ & $1.45, \mathrm{~m}$ & 4 & 19 & $3,4,6,7$ \\
6 & $41.7, \mathrm{CH}_{2}$ & $1.40, \mathrm{~m}$ & & 19 & $4,5,7,8,19$ \\
7 & $72.7, \mathrm{C}$ & & & & \\
8 & $41.3, \mathrm{CH}_{2}$ & $1.49, \mathrm{t}(7.8)$ & 9 & 10,19 & $6,7,9,10,19$ \\
9 & $22.8, \mathrm{CH}_{2}$ & $2.07, \mathrm{dt}(7.0,7.8)$ & 8,10 & 19 & $7,8,10,11$ \\
10 & $128.6, \mathrm{CH}$ & $5.25, \mathrm{t}(7.0)$ & 9,18 & 8,12 & $8,9,12,13,18$ \\
11 & $131.6, \mathrm{C}$ & & & & \\
12 & $48.1, \mathrm{CH}_{2}$ & $2.11, \mathrm{~d}(6.9)$ & 13 & 10,14 & $10,11,13,14,18$ \\
13 & $65.9, \mathrm{CH}^{2}$ & $4.41, \mathrm{dt}(8.2,6.9)$ & 12,14 & 17,18 & $11,12,14,15$ \\
14 & $127.5, \mathrm{CH}^{2}$ & $5.13, \mathrm{~d}(8.2)$ & $13,16,17$ & 12,16 & $12,13,16,17$ \\
15 & $134.8, \mathrm{C}$ & & & & \\
16 & $25.7, \mathrm{CH}_{3}$ & 1.69, br.s & 14 & 14 & $14,15,17$, \\
17 & $18.2, \mathrm{CH}_{3}$ & 1.66, br.s & 14 & 13 & $14,15,16$, \\
18 & $16.1, \mathrm{CH}_{3}$ & 1.65, br.s & 10 & 13 & $10,11,12$ \\
19 & $26.7, \mathrm{CH}_{3}$ & $1.14, \mathrm{~s}$ & & $5,6,8,9$ & $6,7,8$ \\
20 & $16.2, \mathrm{CH}_{3}$ & 1.65, br.s & 2 & 1 & $2,3,4$ \\
\hline
\end{tabular}

The assignment of four isolated spin systems in $\mathbf{1}$ (Figure S1) was provided by chemical shift and coupling constant data, combined with the ${ }^{3} J_{(\mathrm{H}-\mathrm{H})}$ and long-range $g \mathrm{COSY}$ correlations (Table 1, Figure S4) observed between $\mathrm{H}-1 / \mathrm{H}-2, \mathrm{H}-1 / \mathrm{H}_{3}-20$ and $\mathrm{H}-2 / \mathrm{H}_{3}-20$ for partial structure $\mathrm{C}-1 / \mathrm{C}-2 / \mathrm{C}-3 / \mathrm{C}-20$, between $\mathrm{H}_{2}-4 / \mathrm{H}_{2}-5$ for segment $\mathrm{C}-4 / \mathrm{C}-5$; between $\mathrm{H}_{2}-8 / \mathrm{H}_{2}-9, \mathrm{H}_{2}-9 / \mathrm{H}-10$, and $\mathrm{H}-10 / \mathrm{H}_{3}-18$ for spin system C-8/C-9/C-10/C-11/C-18; and between $\mathrm{H}_{2}-12 / \mathrm{H}-13, \mathrm{H}-13 / \mathrm{H}-14, \mathrm{H}-14 / \mathrm{H}_{3}-16$, and $\mathrm{H}-14 / \mathrm{H}_{3}-17$ for fragment $\mathrm{C}-12 / \mathrm{C}-13 / \mathrm{C}-14 / \mathrm{C}-15 / \mathrm{C}-16(\mathrm{C}-17)$. The elucidation of the planar structure shown for 1, confidently established by connecting these segments, was based on the heteronuclear couplings observed in the $g \mathrm{HMBC}$ spectrum (Figures S1 and S6) that were also used to verify the structure of the fragments themselves. The correlations of methylene protons $\mathrm{H}_{2}-4$ with olefinic carbons C-2, C-3, and vinyl methyl C-20-along with those of C-4 with $\mathrm{H}_{3}-20$ and the olefinic proton $\mathrm{H}-2$ - confirmed the connection of carbons $\mathrm{C}-3$ and C-4. Heteronuclear long-range couplings between C-4 and C-5 with $\mathrm{H}_{2}-6$, and also of methylene carbon C- 6 with $\mathrm{H}_{2}-4$ and $\mathrm{H}_{2}-5$ protons, secured the connectivity of $\mathrm{C}-5$ with C-6. HMBC correlations were observed from $\mathrm{H}_{3}-19$ to $\mathrm{C}-6\left(\delta_{\mathrm{C}} 41.7\right)$, the oxygenated carbon $C-7\left(\delta_{C} 72.7\right)$ and $C-8\left(\delta_{C} 41.3\right)$, as well as between $C-19 / \mathrm{H}_{2}-6$ and $\mathrm{C}-19 / \mathrm{H}_{2}-8$. 
Additional cross-peaks between C-7 and three methylene groups $\left(\mathrm{H}_{2}-5, \mathrm{H}_{2}-6\right.$, and $\left.\mathrm{H}_{2}-8\right)$, established the linkage of C-8 and C-6 through the carbinol carbon atom, C-7. Finally, diagnostic $g \mathrm{HMBC}$ couplings between $\mathrm{H}_{2}-12 / \mathrm{C}-10, \mathrm{H}_{2}-12 / \mathrm{C}-11$, and $\mathrm{H}_{2}-12 / \mathrm{C}-18$; between $\mathrm{H}-10 / \mathrm{C}-12$ and $\mathrm{C}-12 / \mathrm{H}_{3}-18$; and finally between $\mathrm{C}-11$ and $\mathrm{H}-13$ established the connection of methylene $\mathrm{C}-12$ and quaternary olefinic $\mathrm{C}-11$. This allowed the completion of the gross structure of $\mathbf{1}$ as a new acyclic diterpene bearing three $\mathrm{OH}$ groups at C-1, C-7, and C-13 (Figure S1), the latter two carbons being chiral.

Extended NOESY experiments in conjunction with ${ }^{1} \mathrm{H}$ and ${ }^{13} \mathrm{C}-\mathrm{NMR}$ chemical shifts and coupling constants interpretation failed to elucidate the overall relative stereochemistry of $\mathbf{1}$. However, the assignment of the double bond configurations at $\Delta^{2}$ and $\Delta^{10}$ with the E-geometry was secured by prominent spatial NOE correlations observed between $\mathrm{H}-2 / \mathrm{H}_{2}-4$ and $\mathrm{H}_{2}-1 / \mathrm{H}_{3}-20$ (for $\Delta^{2}$ ), as well as $\mathrm{H}-10 / \mathrm{H}_{2}-12$ and $\mathrm{H}-10 / \mathrm{H}_{2}-8$ and $\mathrm{H}_{3}-18 / \mathrm{H}-13$ (for $\Delta^{10}$ ). The designation of $\mathrm{H}_{3}-16$ as pro- $E$ and $\mathrm{H}_{3}-17$ as pro- $\mathrm{Z}$ was based on the correlations between $\mathrm{H}_{3}-16$ and olefinic $\mathrm{H}-14$, and between $\mathrm{H}_{3}-17$ and $\mathrm{H}-13$ (Figure S1). The adopted geometries were also supported by the relative upfield chemical shifts of the corresponding vinylic methyl groups (C-20: $\delta_{\mathrm{C}} 16.2$, C-18: $\left.\delta_{\mathrm{C}} 16.1, \mathrm{C}-17: \delta_{\mathrm{C}} 18.2\right)$.

\subsection{Absolute Configuration Assignment by VCD and ${ }^{13} C-N M R$ Spectroscopy}

Based on our previous experience, concentrations of $0.5 \mathrm{M}$ are necessary in order to achieve good signal to noise ratio for a VCD-based AC assignment. Bifurcatriol (1) was in that sense a challenging sample, as only a few milligrams were available. Nevertheless, we recorded the IR and VCD spectra of 1 for a solution of the available $4.7 \mathrm{mg}$ in $60 \mu \mathrm{L}$ of benzene- $d_{6}$, which resulted in a concentration of $0.24 \mathrm{M}$. The obtained spectra are compared to the previously recorded spectra of elegandiol (2) and bifurcane (3) [22] shown in Figure 2. Although more noisy, some characteristic similarities with $\mathbf{2}$ and 3 can be identified in the spectra of $\mathbf{1}$, highlighted green in Figure 2. In particular, the strong negative VCD band at $1153 \mathrm{~cm}^{-1}$ and the onset of the positive bands at 1255 and $1050 \mathrm{~cm}^{-1}$ suggest the possibility of the same (13S)-configuration in $\mathbf{1}$ as for the previously characterized linear diterpenes $\mathbf{2}$ and $\mathbf{3}$.

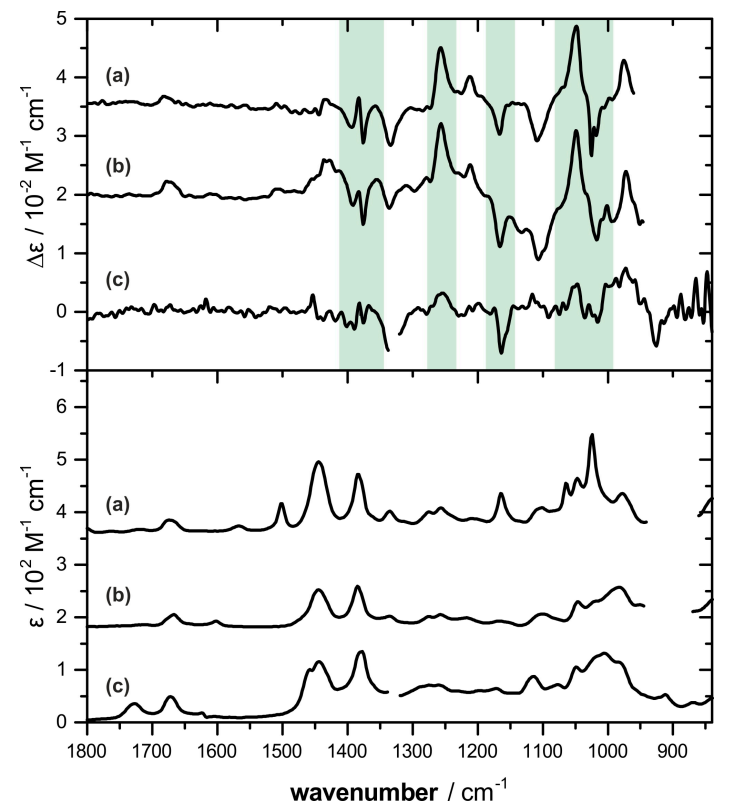

Figure 2. Comparison of the VCD (top) and IR (bottom) spectra of bifurcatriol (1) (traces c, measured in benzene- $d_{6}$ ) against elegandiol (2) (traces $\mathrm{b}, \mathrm{CDCl}_{3}$ ) and bifurcane (3) (traces a, $\mathrm{CDCl}_{3}$ ) reported previously [22]. The green shaded VCD signatures appear to be characteristic for the $\mathrm{C}-13$ stereocenter. Spectral regions around $1340 \mathrm{~cm}^{-1}$ (traces c) and between $950-870 \mathrm{~cm}^{-1}$ (traces a and b) are left out due to solvent absorbance. 
Assuming a (13S)-configuration, we then calculated IR and VCD spectra for (7S,13S)-1 and $(7 R, 13 S)-1$. The generation of the structures of both stereoisomers were followed by a conformational search on a force field level (MMFF using Spartan 14 [24], Monte-Carlo approach). The 100 lowest energy structures of both sets of optimized geometries were subjected to further geometry optimization at density functional theory (DFT) level at the B3LYP/6-31G(2d,p)/IEFPCM (benzene) level of theory. Although the MMFF conformational searches for both stereoisomers were repeated for several initial geometries, less than 10 conformers were found to account for $\sim 95 \%$ of the conformation population after the DFT optimizations. Therefore, the 20 lowest energy structures obtained from this DFT-based pre-optimization were submitted to another optimization cycle at the B3LYP / 6-311++G(2d,p)/IEFPCM (benzene) level of theory. The final computed IR and VCD spectra were obtained by Boltzmann-averaging of the single-conformer spectra according to the populations calculated for $\Delta \mathrm{G}_{298 \mathrm{~K}}$.

In comparison with the experimental spectra, both sets of spectra agree moderately owing to the high noise level of the experimental VCD spectrum. As indicated in Figure 3, the calculated spectral features in the ranges $1400-1230 \mathrm{~cm}^{-1}$ and $1050-1000 \mathrm{~cm}^{-1}$ show very similar pattern, so that both confirm the (13S)-configuration of $\mathbf{1}$. In turn, the computed VCD spectra of the two possible stereoisomers feature only very few bands, which are suited to differentiate between them. Mainly, this is the case in the spectral range from 1230 to $1130 \mathrm{~cm}^{-1}$, in which the $(7 S, 13 S)$-isomer features generally weaker and mostly negative bands while the $(7 R, 13 S)$-isomer features a strong positive component at $\sim 1170 \mathrm{~cm}^{-1}$. When examining the single-conformer spectra of the main conformers (Figure S10), this difference in the band pattern can be assumed to be characteristic for the C7-stereocenter, as it is found to be essentially constant in all spectra. Based on the lack of this strong positive feature, and the qualitatively better agreement of the other VCD spectral signatures as well as of the IR spectral pattern, the absolute configuration of $\mathbf{1}$ was tentatively assigned to be $(7 S, 13 S)$.

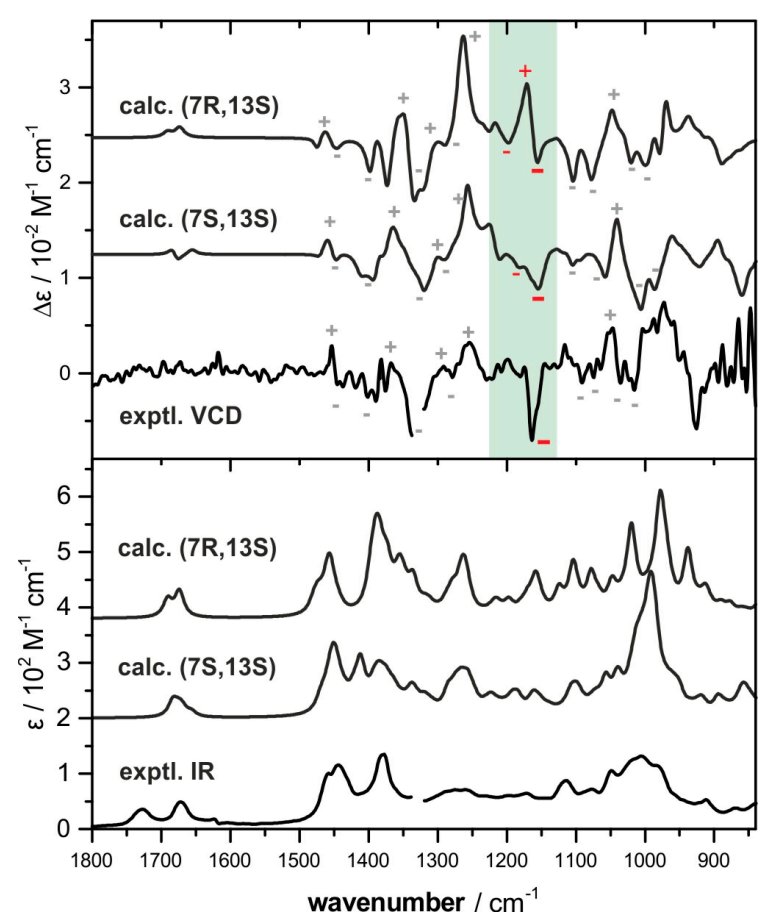

Figure 3. Comparison of the VCD (top) and IR (bottom) spectra of bifurcatriol 1 (measured in benzene- $d_{6}$ ) with those calculated for $(7 S, 13 S)-\mathbf{1}$ and $(7 R, 13 S)-\mathbf{1}$. The green shaded VCD signatures appear to be characteristic for the stereocenter at C-7. Spectral regions around $1340 \mathrm{~cm}^{-1}$ and below $900 \mathrm{~cm}^{-1}$ are left out due to solvent absorbance and high noise. 
In order to further support this assignment, we took advantage of a probability measure recently developed by Goodman and co-workers [25]. This so-called DP4 probability is capable of distinguishing between two or more diastereomers (but not enantiomers) based on a comparison of calculated NMR chemical shifts with experimental data (Figure S11). For this comparison, it is necessary to calculate the NMR shielding constants for every conformer, and subsequently determine the chemical shifts for each atom by Boltzmann averaging over the single-conformer values (Table S1). The GIAO NMR shift calculation is integral part of a VCD intensity calculation, and thus these values are usually available after the VCD spectral analysis. Combining an IR/VCD spectroscopic analysis can thus easily be supplemented by the DP4 probability [26]. In the present case, however, the NMR and vibrational spectra were recorded in different solvents, so that the geometries of 1 used to simulate the IR and VCD spectra were subjected to another cycle of optimization and GIAO NMR shift calculation employing the IEFPCM of benzene. Afterwards, the predicted ${ }^{13} \mathrm{C}-\mathrm{NMR}$ shifts shown in Table S2 were obtained by referencing the obtained shielding constants to the shielding constant of TMS, which has been calculated at the same level of theory. These numbers were then submitted to the web applet for the calculation of DP4 probabilities provided by Goodman et al. [25] which gave a $100 \%$ confidence for 1 having a $(7 S, 13 S)$-configuration. This high confidence of the algorithm certainly has to be interpreted with caution, as there is not yet much data on its performance on highly flexible molecules. However, in light of the fact that it agrees with the conclusion drawn from the VCD analysis, we see it as confirmation. Hence the structure of bifurcatriol was identified as (2E,7S,10E,13S)-3,7,11,15-tetramethylhexadeca-2,10,14-triene-1,7,13-triol.

\subsection{Bioactivity}

Bifurcatriol (1) was evaluated for its in vitro antiprotozoal activity: towards a panel composed of Plasmodium falciparum, Trypanosoma brucei rhodesiense, T. cruzi, and Leishmania donovani; and against L6 primary rat myoblast cells to assess its general cytotoxicity. As shown in Table 2, 1 showed remarkable activity against drug resistant $\mathrm{K} 1$ strain of the malaria parasite, $P$. falciparum with an $\mathrm{IC}_{50}$ value of $0.65 \mu \mathrm{g} / \mathrm{mL}$. The general toxicity against L6 cells was $56.6 \mu \mathrm{g} / \mathrm{mL}$, indicating that 1 has a high selectivity index of 87 . The activity against other protozoan species was only moderate, with $\mathrm{IC}_{50}$ values of $11.8 \mu \mathrm{g} / \mathrm{mL}$ (T. brucei rhodesiense), $47.8 \mu \mathrm{g} / \mathrm{mL}$ (T. cruzi), and $18.8 \mu \mathrm{g} / \mathrm{mL}$ (L. donovani). This indicates that $\mathbf{1}$ has specific antiplasmodial activity with good selectivity.

Table 2. In vitro antiprotozoal activity of bifurcatriol (1). $\mathrm{IC}_{50}$ values are in $\mu \mathrm{g} / \mathrm{mL}$. Reference compounds ${ }^{\mathrm{a}}$ chloroquine, ${ }^{\mathrm{b}}$ melarsoprol, ${ }^{\mathrm{c}}$ benznidazole, ${ }^{\mathrm{d}}$ miltefosine, ${ }^{\mathrm{e}}$ podophyllotoxin. Cytotoxicity was evaluated against the L6 rat myoblast cell line.

\begin{tabular}{cccccc}
\hline Compound & P.falciparum & T. $\boldsymbol{b}$. rhodesiense & T. cruzi & L.donovani & Cytotoxicity \\
\hline 1 & 0.65 & 11.8 & 47.8 & 18.8 & 56.6 \\
Reference & $0.05^{\mathrm{a}}$ & $0.01^{\mathrm{b}}$ & $0.59^{\mathrm{c}}$ & $0.12^{\mathrm{d}}$ & $0.004^{\mathrm{e}}$ \\
\hline
\end{tabular}

\section{Discussion}

Determination of the AC of natural products is crucial for their bioactivity/toxicity, feasibility for organic synthesis, and identification of biogenetic origin, yet it remains mostly very demanding or problematic [15]. The major challenge in the structural elucidation of the linear diterpenes isolated from B. bifurcata and other members of the Sargassaceae family rests in the determination of the AC of their oxidized stereocenters. Due to the inherent incapacity of these compounds to shape crystals suitable for X-ray crystallographic analyses, the most frequently used method for AC determination is Horeau's and Mosher's derivatization approaches. However, the proximity of additional hydroxyls, difficulties in the assignment of diagnostic derivative protons, or steric hindrances in asymmetric quaternary carbon environments - as in the case of $\mathbf{1}$-renders the NMR anisotropy method insufficient $[10,11]$. The absolute configuration of $\mathbf{1}$ has been assigned based on the results of VCD spectroscopy and DP4 
probability analyses of the calculated ${ }^{13} \mathrm{C}-\mathrm{NMR}$ chemical shifts. The combination of two techniques for the assignment was necessary, as the available amounts of $\mathbf{1}$ did not allow us to measure the VCD spectrum at an optimum concentration. As a result, the VCD spectrum was rather noisy and did not allow for an unambiguous assignment. The DP4 analysis, however, allowed us to clearly distinguish the diastereomers based on the predicted ${ }^{13} \mathrm{C}-\mathrm{NMR}$ shifts, and thus to confirm the structure of the target compound. The present study thus showcases the power of joining methods for the assignment of AC [27]. To our knowledge, $\mathbf{1}$ is the first acyclic natural product with two stereogenic centers whose AC assignment was simultaneously and successfully determined via a combined VCD and DP4/NMR analyses without further derivatization. Furthermore, bifurcatriol (1) appears to be a lead compound whose antimalarial activity can be improved by medicinal chemistry approaches.

\section{Materials and Methods}

\subsection{General Experimental Procedures}

Optical rotations were determined at the sodium D line $(589.3 \mathrm{~nm})$, at $20^{\circ} \mathrm{C}$, with a $10 \mathrm{~cm}$ cell, on a Unipol L1000 Schmidt + Haensch polarimeter. UV spectra were acquired in spectroscopic grade $\mathrm{CHCl}_{3}$ on a Varian, Cary 100 UV-Vis spectrophotometer. IR spectra were recorded on a Perkin Elmer 400 ATR FT-IR spectrometer. NMR spectra were acquired using a Varian $500 \mathrm{MHz}$ spectrometer. Chemical shifts are given on the $\delta(\mathrm{ppm})$ scale, referenced to the residual solvent signal $\left(\mathrm{CDCl}_{3}: \delta_{\mathrm{H}} 7.24, \delta_{\mathrm{C}} 77.0\right)$, and coupling constant values $(J)$ are reported in Hz. High resolution mass spectrometric data were measured on an Agilent 1290 Infinity UPLC system, operating on the elution gradient: $50 \%$ B for 8 min, increasing to $100 \% \mathrm{~B}$ in $3 \mathrm{~min}$, maintaining $100 \%$ B for 5 min (solvent $\mathrm{A}: \mathrm{H}_{2} \mathrm{O}+0.1 \%$ formic acid, solvent B: MeCN + 0.1\% formic acid), on a ZORBAX Eclipse Plus RRHD C18 $(50 \times 2.1 \mathrm{~mm}, 1.8 \mu \mathrm{m})$ column, flow $0.5 \mathrm{~mL} / \mathrm{min}$, UV detection 200-600 nm, combined with an Agilent 6540 QTOF system, with electrospray ionization (ESI) in the positive ion mode. Thin layer chromatography was performed on silica gel $60 \mathrm{~F}_{254}$ supported on aluminum sheets (Merck, Tullagreen, Ireland). Substances were detected by UV at 254 and $366 \mathrm{~nm}$ or after spraying with $6 \%$ vanillin and $15 \% \mathrm{H}_{2} \mathrm{SO}_{4}$ in $\mathrm{MeOH}$ reagents and charring. All solvents were of HPLC or LC-MS grade and were purchased from Sigma-Aldrich (Arklow, Ireland).

\subsection{Algal Material}

Bifurcaria bifurcata was collected by hand from the intertidal rock pool at Kilkee, County Clare of Ireland, in May of 2009 and kept frozen until the work-up. A voucher specimen (BDV0015) is kept at the Herbarium of the Biodiscovery Laboratory in the Irish Marine Institute.

\subsection{Extraction and Isolation}

The freeze-dried algal material (132.4 g dry weight) was exhaustively extracted at room temperature consecutively with $\mathrm{CH}_{2} \mathrm{Cl}_{2}$ and $\mathrm{MeOH}$. The combined extracts were concentrated to give a dark green residue $(12.0 \mathrm{~g})$ that was subjected to a modified Kupchan partition scheme. Briefly, the crude extract was partitioned between $10 \%$ aqueous $\mathrm{MeOH}$ and $n$-hexane. The water concentration of the aq. $\mathrm{MeOH}$ phase was increased to $35 \%$, before partitioning against $\mathrm{CHCl}_{3}$. Evaporation of the solvent under reduced pressure afforded the $\mathrm{CHCl}_{3}$ subextract $(7.6 \mathrm{~g})$, which was subjected to automated Flash chromatography fractionation on an Agilent 971FP system loaded with a pre-packed Varian SuperFlash Si50 SF25-80g silica column $(277 \times 28.2 \mathrm{~mm}, 50 \mu \mathrm{m})$, operating the gradient: $0 \%$ B for $5 \mathrm{~min}$, increasing to $5 \% \mathrm{~B}$ in $15 \mathrm{~min}$, maintaining $5 \%$ B for $10 \mathrm{~min}$, increasing to $10 \% \mathrm{~B}$ in $10 \mathrm{~min}$, maintaining $10 \% \mathrm{~B}$ for $10 \mathrm{~min}$, increasing to $40 \% \mathrm{~B}$ in $40 \mathrm{~min}$, increasing to $100 \% \mathrm{~B}$ in $10 \mathrm{~min}$, maintaining $100 \%$ B for 10 min (solvent A: $n$-hexane, solvent B: EtOAc), at a flow of 25 $\mathrm{mL} / \mathrm{min}$, collecting $25 \mathrm{~mL}$ fractions. Combined fractions 63 and 64 that eluted with $80 \%$ EtOAc in n-hexane (19.5 mg) were subjected to RP-HPLC. The separation was conducted using an Agilent 1260 HPLC system equipped with a diode array and an ELSD detector (split flow) on a Kromasil 100 
C18 $(250 \times 8 \mathrm{~mm}, 5 \mu \mathrm{m}) \mathrm{HPLC}$ reversed-phase column. The elution gradient was: $55 \% \mathrm{~B}$ for $13 \mathrm{~min}$, increasing to $100 \% \mathrm{~B}$ in $5 \mathrm{~min}$, maintaining $100 \% \mathrm{~B}$ for 20 min (solvent $\mathrm{A}: \mathrm{H}_{2} \mathrm{O}$, solvent $\mathrm{B}: \mathrm{MeCN}$ ), at a flow of $1.5 \mathrm{~mL} / \mathrm{min}$, and afforded $1 \mathrm{in}$ pure state $\left(7.7 \mathrm{mg}, 0.007 \%, t_{\mathrm{R}} 16.3 \mathrm{~min}\right)$.

Bifurcatriol (1): colorless oil; $[\alpha]_{\mathrm{D}}^{25}-3.0\left(c 0.6, \mathrm{CHCl}_{3}\right) ; \mathrm{UV}\left(\mathrm{CHCl}_{3}\right) \lambda_{\max }(\log \varepsilon) 245$ (2.31) nm; IR (film) $v_{\max } 3354,2968,2930,1670 \mathrm{~cm}^{-1} ;{ }^{1} \mathrm{H}-\mathrm{NMR}\left(\mathrm{CDCl}_{3}, 500 \mathrm{MHz}\right)$ and ${ }^{13} \mathrm{C}-\mathrm{NMR}\left(\mathrm{CDCl}_{3}, 125 \mathrm{MHz}\right)$ see Table 1; HRMS (ESI-TOF) $m / z 347.2559[\mathrm{M}+\mathrm{Na}]^{+}$(calcd for $\mathrm{C}_{20} \mathrm{H}_{36} \mathrm{O}_{3} \mathrm{Na}, 347.2557$ ).

\subsection{IR and VCD Spectroscopy}

The IR and VCD spectra were recorded on a Bruker Vertex $70 \mathrm{~V}$ spectrometer equipped with a PMA 50 module for polarization modulated measurements. Samples were held in a sealed $\mathrm{BaF}_{2} \mathrm{IR}$ cell with $100 \mu \mathrm{m}$ path length. Both IR and VCD spectra were recorded at $4 \mathrm{~cm}^{-1}$ spectral resolution by accumulating $\sim 20,000$ scans ( $4 \mathrm{~h}$ accumulation time for VCD). Baseline correction of the spectra was done by subtraction of the solvent spectra measured under identical conditions.

\subsection{Computational Analysis}

Force field (MMFF94) based conformational analysis of 1 was carried out using the implemented algorithms of Spartan 14 [24]. DFT-based geometry optimizations and spectra calculations were carried out using Gaussian 09 D.01 [28] employing the B3LYP functional and the 6-31G(2d,p) and $6-311++\mathrm{G}(2 \mathrm{~d}, \mathrm{p})$ basis set. All calculations were carried out considering implicit solvation with a polarizable continuum model for benzene and chloroform. Lorentzian band shapes with $8 \mathrm{~cm}^{-1}$ half-width at half height were assigned to the calculated dipole and rotational strength, and the frequencies were scaled by a factor of 0.975 for better visual comparison.

\subsection{Antiprotozoal Activity}

The in vitro antiparasitic activities of $\mathbf{1}$ (Table 2) against P. falciparum (K1 strain), T. cruzi, T. brucei rhodesiense, L. donovani, and the cytotoxicity against rat skeletal myoblast L6 cells were determined as described previously [29].

Supplementary Materials: The following are available online at www.mdpi.com/1660-3397/15/8/245/s1, Figure S1: Key HMBC COSY and NOESY correlations observed in compound 1, Figure S2: ${ }^{1} \mathrm{H}-\mathrm{NMR}$ spectrum $(500 \mathrm{MHz}$, $\mathrm{CDCl}_{3}$ ) of compound 1, Figure S3: ${ }^{13} \mathrm{C}-\mathrm{NMR}$ spectrum $\left(125 \mathrm{MHz}, \mathrm{CDCl}_{3}\right)$ of compound 1, Figure S4: gCOSY spectrum $\left(500 \mathrm{MHz}, \mathrm{CDCl}_{3}\right)$ of compound 1, Figure S5: gHSQC spectrum $\left(500 / 125 \mathrm{MHz}, \mathrm{CDCl}_{3}\right)$ of compound 1, Figure S6: gHMBC spectrum (500/125 MHz, $\mathrm{CDCl}_{3}$ ) of compound 1, Figure S7: NOESY spectrum $(500 \mathrm{MHz}$, $\mathrm{CDCl}_{3}$ ) of compound 1, Figure S8: ESI HR-MS report for compound 1, Figure S9: FT-IR (ATR) spectrum of compound 1, Figure S10: Comparison of the calculated VCD spectra of some key conformers of both possible stereoisomers, Figure S11: Correlation of experimental and predicted ${ }^{13} \mathrm{C}-\mathrm{NMR}$ chemical shifts of $(7 S, 13 S)-\mathbf{1}$ and $(7 R, 13 S)-1$, Table S1: Comparison of experimental and calculated ${ }^{13} \mathrm{C}$ chemical shifts (CDCl3), Table S2: Calculated ${ }^{13} \mathrm{C}$-chemical shifts for $(7 S, 13 S)-\mathbf{1}$ and $(7 R, 13 S)-\mathbf{1}$ (b3lyp/6-311++G(2d,p)/IEFPCM $\left./ \mathrm{CHCl}_{3}\right)$.

Acknowledgments: The authors thank $\mathrm{S}$. Heesch for collection and identification of the algal material. We also thank M. Cal, S. Keller-Märki, and Romina Rocchetti for parasite assay results. Part of this work was financially supported by the Beaufort Marine Research Award, carried out under the Sea Change Strategy and the Strategy for Science Technology and Innovation (2006-2013), with the support of the Marine Institute, and funded under the Marine Research Sub-Programme of the National Development Plan 2007-2013. C.M. thanks the Fonds der ChemischenIndustrie (FCI) for a Liebig fellowship and furthermore acknowledges financial support by the Deutsche Forschungsgemeinschaft (DFG) through the Cluster of Excellence RESOLV ("Ruhr Explores SOLVation", EXC 1069).

Author Contributions: Vangelis Smyrniotopoulos and Deniz Tasdemir conceived and designed the experiments; Vangelis Smyrniotopoulos performed extraction, isolation, and gross structure elucidation; Christian Merten performed VCD and DFT studies; Marcel Kaiser carried out antiprotozoal assays; Vangelis Smyrniotopoulos and Deniz Tasdemir analyzed the data; Vangelis Smyrniotopoulos and Deniz Tasdemir wrote the paper. All authors contributed and approved the final version.

Conflicts of Interest: The authors declare no conflict of interest. 


\section{References}

1. Jackson, M.B. Nature's chemicals. The natural products that shaped our world. Ann. Bot. 2010, 106, vi-vii. [CrossRef]

2. Salmon, M.; Laurendon, C.; Vardakou, M.; Cheema, J.; Defernez, M.; Green, S.; Faraldos, J.A.; O’Maille, P.E. Emergence of terpene cyclization in Artemisia annua. Nat. Commun. 2015, 6, 6143. [CrossRef] [PubMed]

3. Singh, B.; Sharma, R.A. Plant terpenes: Defense responses, phylogenetic analysis, regulation and clinical applications. 3 Biotech 2015, 5, 129-151. [CrossRef] [PubMed]

4. Koga, Y.; Morii, H. Recent advances in structural research on ether lipids from Archaea including comparative and physiological aspects. Biosci. Biotechnol. Biochem. 2005, 69, 2019-2034. [CrossRef] [PubMed]

5. McGarvey, D.J.; Croteau, R. Terpenoid metabolism. Plant Cell 1995, 7, 1015-1026. [CrossRef] [PubMed]

6. Gershenzon, J.; Dudareva, N. The function of terpene natural products in the natural world. Nat. Chem. Biol. 2007, 3, 408-414. [CrossRef] [PubMed]

7. Cal, K. Across skin barrier: Known methods, new performances. In Frontiers in Drug Design and Discovery; Rahman, A.U., Caldwell, G.W., Eds.; Bentham Science Publishers Ltd.: Sharjah, UAE, 2009; Volume 4, pp. 162-188.

8. Maschek, J.A.; Baker, B.J. The chemistry of algal secondary metabolism. In Algal Chemical Ecology; Amsler, C.D., Ed.; Springer: Berlin/Heidelberg, Germany, 2008; pp. 1-24.

9. Young, R.M.; Schoenrock, K.M.; von Salm, J.L.; Amsler, C.D.; Baker, B.J. Structure and function of macroalgal natural products. In Natural Products from Marine Algae: Methods and Protocols; Stengel, B.D., Connan, S., Eds.; Springer: New York, NY, USA, 2015; pp. 39-73.

10. Amico, V. Marine brown algae of family Cystoseiraceae: Chemistry and chemotaxonomy. Phytochemistry 1995, 39, 1257-1279. [CrossRef]

11. Muñoz, J.; Culioli, G.; Köck, M. Linear diterpenes from the marine brown alga Bifurcaria bifurcata: A chemical perspective. Phytochem. Rev. 2013, 12, 407-424. [CrossRef]

12. Rindi, F.; Soler-Vila, A.; Guiry, M.D. Taxonomy of marine macroalgae used as sources of bioactive compounds. In Marine Bioactive Compounds: Sources, Characterization and Applications; Hayes, M., Ed.; Springer: Boston, MA, USA, 2012; pp. 1-53.

13. Petrovic, A.G.; Berova, N.; Alonso-Gómez, J.L. Absolute configuration and conformational analysis of chiral compounds via experimental and theoretical prediction of chiroptical properties: ORD, ECD, and VCD. In Structure Elucidation in Organic Chemistry; Wiley-VCH Verlag GmbH \& Co. KGaA: Weinheim, Germany, 2015; pp. 65-104.

14. Blackmond, D.G. The origin of biological homochirality. Cold Spring Harb. Perspect. Biol. 2010, 2, a002147. [CrossRef] [PubMed]

15. Batista, J.M., Jr.; da Silva Bolzani, V. Chapter 13: Determination of the absolute configuration of natural product molecules using Vibrational Circular Dichroism. In Studies in Natural Products Chemistry; Rahman, A.U., Ed.; Elsevier: Amsterdam, The Netherlands, 2014; Volume 41, pp. 383-417.

16. Batista, J.M., Jr.; Blanch, E.W.; da Silva Bolzani, V. Recent advances in the use of vibrational chiroptical spectroscopic methods for stereochemical characterization of natural products. Nat. Prod. Rep. 2015, 32, 1280-1302. [CrossRef] [PubMed]

17. Stephens, P.J.; Devlin, F.J.; Cheeseman, J.R. VCD Spectroscopy for Organic Chemists; CRC Press: Boca Raton, FL, USA, 2012.

18. Sprenger, R.F.; Thomasi, S.S.; Ferreira, A.G.; Cass, Q.B.; Batista, J.M., Jr. Solution-state conformations of natural products from chiroptical spectroscopy: The case of isocorilagin. Org. Biomol. Chem. 2016, 14, 3369-3375. [CrossRef] [PubMed]

19. Merten, C.; Li, F.; Bravo-Rodriguez, K.; Sanchez-Garcia, E.; Xu, Y.; Sander, W. Solvent-induced conformational changes in cyclic peptides: A vibrational circular dichroism study. Phys. Chem. Chem. Phys. 2014, 16, 5627-5633. [CrossRef] [PubMed]

20. Kreienborg, N.M.; Pollok, C.H.; Merten, C. Towards an observation of active conformations in Asymmetric catalysis: Interaction-induced conformational preferences of a chiral thiourea model compound. Chem. Eur. J. 2016, 22, 12455-12463. [CrossRef] [PubMed]

21. Osowski, T.; Golbek, J.; Merz, K.; Merten, C. Intermolecular interactions of a chiral amine borane adduct revealed by VCD spectroscopy. J. Phys. Chem. A 2016, 120, 4108-4115. [CrossRef] [PubMed] 
22. Merten, C.; Smyrniotopoulos, V.; Tasdemir, D. Assignment of absolute configurations of highly flexible linear diterpenes from the brown alga Bifurcaria bifurcata by VCD spectroscopy. Chem. Commun. 2015, 51, 16217-16220. [CrossRef] [PubMed]

23. Smith, S.G.; Goodman, J.M. Assigning stereochemistry to single diastereoisomers by GIAO NMR calculation: The DP4 probability. J. Am. Chem. Soc. 2010, 132, 12946-12959. [CrossRef] [PubMed]

24. Spartan 14; Wavefunction Inc.: Irvine, CA, USA, 2014.

25. The Goodman Group Highlights Page: Assignment of Stereochemistry and Structure Using NMR and DP4. Available online: http:/ / www-jmg.ch.cam.ac.uk/tools/nmr/DP4/ (accessed on 15 May 2017).

26. Merten, C.; Dirkmann, M.; Schulz, F. Stereochemical assignment of fusiccocadiene from NMR shielding constants and vibrational circular dichroism spectroscopy. Chirality 2017. [CrossRef] [PubMed]

27. De Gussem, E.; Herrebout, W.; Specklin, S.; Meyer, C.; Cossy, J.; Bultinck, P. Strength by joining methods: Combining synthesis with NMR, IR, and Vibrational Circular Dichroism spectroscopy for the determination of the relative configuration in hemicalide. Chem. Eur. J. 2014, 20, 17385-17394. [CrossRef] [PubMed]

28. Frisch, M.J.; Trucks, G.W.; Schlegel, H.B.; Scuseria, G.E.; Robb, M.A.; Cheeseman, J.R.; Scalmani, G.; Barone, V.; Mennucci, B.; Petersson, G.A.; et al. Gaussian 09, Revision D.01; Gaussian, Inc.: Wallingford, CT, USA, 2013.

29. Atay, I.; Kirmizibekmez, H.; Kaiser, M.; Akaydin, G.; Yesilada, E.; Tasdemir, D. Evaluation of in vitro antiprotozoal activity of Ajuga laxmannii and its secondary metabolites. Pharm. Biol. 2016, 54, 1808-1814. [CrossRef] [PubMed]

(C) 2017 by the authors. Licensee MDPI, Basel, Switzerland. This article is an open access article distributed under the terms and conditions of the Creative Commons Attribution (CC BY) license (http://creativecommons.org/licenses/by/4.0/). 